Full Research Paper

\title{
Dietary Flavonoids Sensitize HeLa Cells to Tumor Necrosis Factor-Related Apoptosis-Inducing Ligand (TRAIL)
}

\author{
Ewelina Szliszka, Zenon P. Czuba, Katarzyna Jernas and Wojciech Król * \\ Chair and Department of Microbiology and Immunology, Jordana 19, 41808 Zabrze \\ Medical University of Silesia, Katowice, Poland, Tel. / Fax: +48 0322722554 \\ E-mail: wkrol@sum.edu.pl (W.K.),zczuba@sum.edu.pl (Z. C.) \\ * Author to whom correspondence should be addressed
}

Received: 16 August 2007; in revised form: 3 January 2008 / Accepted: 17 January 2008 /

Published: 21 January 2008

\begin{abstract}
TRAIL is a promising candidate for cancer therapeutics that preferentially induces apoptosis in cancer cells. The combined treatment flavonoids with TRAIL might be promising as a chemoprevention and/or new therapy against malignant tumors. We examined the cytotoxic effect of dietary flavonoids in combination with TRAIL on HeLa cells. It was found that treatment with noncytotoxic concentration of some flavonoids significantly sensititizes to TRAIL induced death in HeLa cells. Our study demonstrated that flavone, apigenin and genistein markedly augmented TRAIL mediated cytotoxicity against HeLa, whereas kaempferol and quercetin produced no effect.
\end{abstract}

Keywords: Dietary flavonoids, TRAIL, HeLa, chemoprevention, antitumoral activity.

\section{Introduction}

Flavonoids are polyphenolic compounds found as integral components in the human diet. They are universally present as constituents of flowering plants, particularly of food plants. The high intake of foods and beverages rich in polyphenols, especially in flavonoids, has been associated with decreased risk of neoplasm. Dietary flavonoids inhibit the proliferation of various cancer cells and tumor growth in animal models [1-4]. Epidemiologic data suggested that flavonoids consumption may protect against cancer induction in several human tissues. Chemoprevention has the potential to be a major component of colon, lung, prostate and bladder cancer control [5,6]. Several of polyphenolic 
compounds regulate the genes that are critical for the control of proliferation, cell cycle and apoptosis pathway in cancer cells [7]. Recently it has been reported that flavonoids sensitized in vitro cancer cells to apoptosis induced by anticancer agents, for example the tumor necrosis factor (TNF)-family members (death ligands) [8-19].

Tumor necrosis factor-related apoptosis-inducing ligand (TRAIL) is a promising candidate for cancer therapeutics due to its ability to selectively induce apoptosis in malignant tumor cells with no toxicity against normal tissues. Soluble or expressed on lymphocytes T, macrophage and NK cells TRAIL play an important role in immune surveillance and defence mechanism against tumor cells. The mechanisms of cytotoxicity are TRAIL mediated induction of tumor cells death [20]. The cytotoxic effector functions of those immune cells are important for enabling the immune system to cope efficiently with malignancy. TRAIL induces apoptosis in various malignant tumor cells through its interaction with the death-domain containing receptor TRAIL-R1 (death receptor 4 - DR4) and/or TRAIL-R2 (death receptor 5 - DR5) [21]. However, some tumor cells are resistant to TRAIL-mediated cytotoxicity. The decreased expression of death receptors TRAIL-R1 and TRAIL-R2 or increased expression of antiapoptotic protein in cancer cells were involved in TRAIL-resistance [22]. The TRAIL-mediated cytotoxicity pathways may be a target of the dietary flavonoids in human tumor cells and the overcome of TRAIL-resistance by flavonoids may be one of the mechanisms responsible for their cancer-preventive effects [8-14].

Luteolin has been reported for the first time to overcome the resistance to TRAIL mediated apoptosis in HeLa cells [10]. Luteolin synergistically sensitizes TRAIL induced apoptosis in HeLa associated with up-regulation of death receptors TRAIL-R2 [11]. These findings suggest that the combined administration of luteolin and TRAIL may be a useful strategy for cancer therapy.

In this study, we show that flavone, apigenin and genistein enhanced TRAIL-mediates cytotoxicity in human cervical HeLa cells, whereas kaempferol and quercetin produced no effect. We demonstrated for the first time activity of those flavonoids differing in chemical structure (presence of hydroxyl group in position 4') on the same cell line. The results of performed experiments demonstrated activities of those dietary flavonoids in TRAIL-mediated cytotoxicity pathway in cancer cells and raised the possibility that combined effect of TRAIL and flavonoids can be used as a promising strategy for prevention or treatment of malignant tumors.

\section{Results and Discussion}

Recently it has been reported that flavonoids sensitized in vitro cancer cells to apoptosis induced by anticancer agents for example the members of the TNF family: TNFalpha, Fas or TRAIL [8-19]. Tumor necrosis factor superfamilly is a group of cytokines with important functions in immunity, inflammation, differentiation, control of cell proliferation, and apoptosis. These cytokines induce cell death through sequential recruitment by death receptors and rapid activation of a cascade of caspases $[23,24]$.

In this study, we investigated the cytotoxic effect of recombinant human TRAIL at the concentrations of $25-200 \mathrm{ng} / \mathrm{ml}$ on human cervical cancer cells. HeLa cell line was relatively resistant to TRAIL mediated cytotoxicity at these concentrations. Flavonoids alone, were similar to TRAIL weakly induced cytotoxicity in HeLa cells. Structures of used flavonoids are shown in Table 1. 
Table 1. Chemical structures of flavonoids used in combination with TRAIL.<smiles>O=c1cc(-c2ccccc2)oc2ccccc12</smiles>

Flavone

(1)<smiles>O=c1c(O)c(-c2ccc(O)c(O)c2)oc2cc(O)cc(O)c12</smiles>

Quercetin

(4)



Apigenin

(2)<smiles>O=c1c(O)c(-c2ccc(O)cc2)oc2cc(O)cc(O)c12</smiles>

Kaempferol

(3)

Genistein

(5)

Pretreatment with dietary flavonoids sensitized HeLa cells to agents that specifically target death receptors (TRAIL, Fas, TNFalpha) [10,11,18].

Next, we tested the cytotoxic effects of dietary flavonoids: flavone, apigenin, kaempferol, quercetin and genistein in combination with TRAIL at the concentrations of $100 \mathrm{ng} / \mathrm{ml}$ on HeLa cell line. There was observed an additive cytotoxic effect on the three flavonoids (flavone, apigenin, genistein) in combination with TRAIL. The two other, kaempferol and quercetin had no effect on TRAIL-mediated cytotoxicity. Inhibitory effects of the flavonoids in combination with TRAIL on HeLa cell line are shown in Table 2.

Table 2. The cytotoxic effects of flavonoids in combination with TRAIL on HeLa cell line measured by MTT method.

\begin{tabular}{ccc}
\hline & Compound & IC $_{\mathbf{5 0}}(\boldsymbol{\mu M})^{\mathbf{a}}$ \\
\hline $\mathbf{1}$ & Flavone & $49.69 \pm 1.08$ \\
$\mathbf{2}$ & Apigenin & $43.05 \pm 0.86$ \\
$\mathbf{3}$ & Kaempferol & $\mathrm{nd}^{\mathrm{b}}$ \\
$\mathbf{4}$ & Quercetin & $\mathrm{nd}$ \\
$\mathbf{5}$ & Genistein & $49.64 \pm 2.43$ \\
\hline
\end{tabular}

${ }^{\mathrm{a}}$ Data shown represent the mean \pm SD of three independent experiments;

${ }^{\mathrm{b}}$ nd (not determined) $-\mathrm{IC}_{50}>50 \mu \mathrm{M} /$ had not effect

Flavone, apigenin, genistein alone exhibited very weak antitumor activity with $\mathrm{IC}_{50}$ values $>50 \mu \mathrm{M}$ (cytotoxicity at concentration $50 \mu \mathrm{M}$ was near zero), but in combination with TRAIL the $\mathrm{IC}_{50}$ values increased to $43.05-49.69 \mu \mathrm{M}$.

The necrotic cell death percentage of cancer cells incubated with flavonoids in combination with or without TRAIL, examined by lactate dehydrohenase (LDH) leakage was around $0 \%$. 
Figure 1. The apoptotic effecs of flavonoids and flavonoids with TRAIL on HeLa cells. Concentration of flavonoids - $50 \mu \mathrm{M}$. The results of studies are expressed as mean values \pm SD from three separate experiments. $*-P<0.05$, ** $-P<0.01$ versus a respective control.

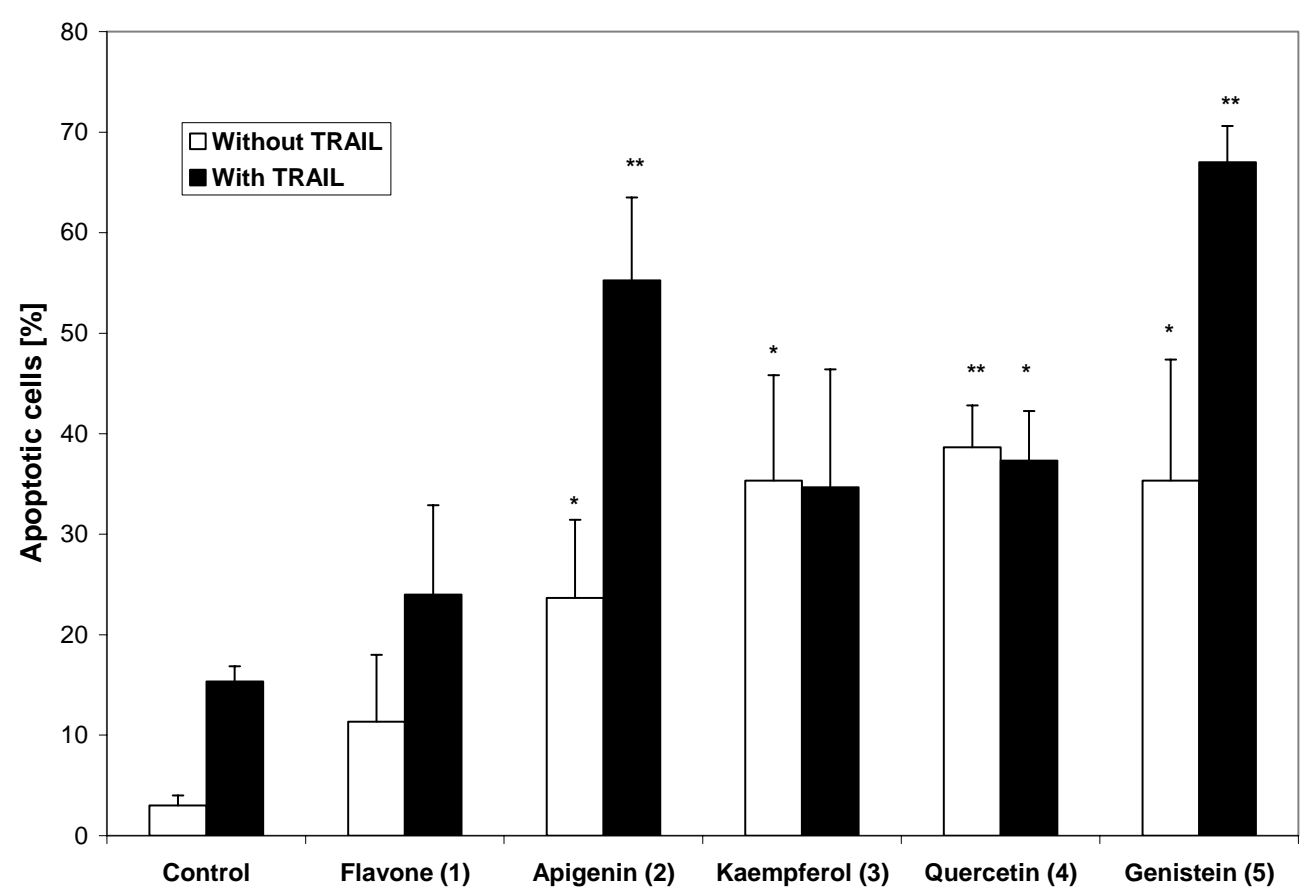

Flavonoids or with TRAIL combination increase the percentage of apoptotic cells (Figure 1). The most activity is marked for apigenin and genistein. Addition of TRAIL to kaempferol or quercetin did not change of the percentage of apoptotic cells. Both kaempferol and quercetin have hydroxyl group in position 3.

Epidemiological and preclinical evidence suggests that polyphenolic phytochemicals posses cancer chemopreventive properties. The use of these agents for cancer prevention is driven by epidemiology supporting the idea that regional diets and consumption of specific dietary component such as soya isoflavones are associated with lower risk for cancer [5,6].

Flavone, apigenin, genistein restored TRAIL sensitivity in TRAIL-resistant HeLa cells. Similar study with apigenin showed sinergistically augments TRAIL - induced apoptosis in human malignant tumor cells: Jurkat cells, prostate cancer DU-145, colon cancer DLD-1. Apigenin partially prevented the degradation of DR5 protein and significantly increased DR5 protein in the membrane fraction, very slightly increased DR5 mRNA and did not enhanced promotor activity [14].

Kaempferol and quercetin in combination with TRAIL demonstrated rather weak inhibitory activity against HeLa cells.

The previous study indicate the strong ROS (reactive oxygen species) accumulation upon TRAIL induction, with activation of caspases, followed by cells death and oxidative stress mediates TRAIL-induced cytotoxicity in HeLa cells [25].

The capability of flavonoids to overcome the resistance to TRAIL induced cytotoxicity in cancer cells might be predicted on the basis of their chemical composition and structure. Our early 
investigation showed stimulation of luminol oxidation by hydrogen peroxide with horseradish peroxidase by apigenin. Kaempferol and quercetin strongly inhibited this reaction. It was dependent on their chemical structures. The presence of hydroxyl group in position 4' (apigenin) stimulated the reaction but hydroxyl group in position 3 and hydroxyl group in position 4' (kaempferol) or two hydroxyl groups in phenyl ring and in position 3 (quercetin ) inhibited this reaction. We hypothesize that observed higher activity of apigenin than quercetin and kaempferol may be partially dependent on their ability to reaction with ROS [26]. To show this dependence comparative analysis of the effects of more flavonoids in combination with TRAIL in cancer cells is required.

Our results suggested that the sensitization of TRAIL-mediated apoptosis may be a target of the dietary flavonoids in tumor cells. Chemopreventive effect of those flavonoids is based on several mechanisms [3,6,9-21]. Induction of ROS by some of them, for example apigenin may play a role as an upstream mediator of caspases $[27,28]$.

The numerous studies confirm a substantial role of endogenously expressed TRAIL as the effector molecule in immunosurveillance that eliminates developing and metastatic tumors [21,22]. However, not all tumor cells are susceptible to TRAIL. It is therefore important to overcome by flawonoids this resistance for the clinical use of TRAIL in chemoprevention and/or cancer therapy. Three tested flavonoids: flavone, apigenin and genistein similar to luteolin [10] markedly augmented the cytotoxicity of TRAIL. Our study confirmed that combined treatment with those dietary flavonoids and TRAIL exhibit high inhibitory activity against cancer cells.

The TRAIL-mediated apoptosis pathways in cancer cells may be one of the targets of anticancer function of flavonoids, and thus provide the molecular basis for the development of dietary flavonoids as a novel chemopreventive agents for tumor malignancy [7-10,14].

\section{Conclusions}

Dietary flavonoids can help overcome the resistance to TRAIL and markedly induce cytotoxicity together with TRAIL in human cervical cancer HeLa cells. These results suggest that flavone, apigenin and genistein may be promising agents for cancer chemoprevention and therapy in combination with TRAIL.

\section{Experimental Section}

\subsection{General}

Flavone, apigenin, kaempferol, quercetin, genistein were obtained from Carl Roth GmbH (Karsruhe, Germany) and Sigma Chemical Company (St. Louis, MO). The reagents were dissolved in DMSO to a final concentration of $0.01 \%$ in media. Soluble recombinant human TRAIL/Apo2L (rhsTRAIL) was purchased from PeproTech Inc. New Jersey, Rocky Hill.

\subsection{Cell culture}

HeLa cervical cancer cell line (DSMZ - Deutsche Sammlung von Mikroorganismen und Zellkulturen GmbH - German Collection of Microorganisms and Cell Cultures, Braunschweig, Germany) was cultured as monolayers and maintained in RPMI 1640 (PAA - The cell culture 
company, Germany through Immuniq, Poland) containing 10\% fetal bovine serum (PAA - The cell culture company, Germany through Immuniq, Poland), $100 \mathrm{U} / \mathrm{ml}$ penicillin and $100 \mu \mathrm{g} / \mathrm{ml}$ streptomycin (PAA - The cell culture company, Germany through Immuniq, Poland) in a humidified atmosphere with $5 \% \mathrm{CO}_{2}$ at $37^{\circ} \mathrm{C}$.

\subsection{Cytotoxicity assay}

MTT (3-(4,5-dimethylthiazol-2-yl)-2,5-diphenyltetrazolium bromide) assay

For the experiments the cells were seeded onto 96-well microtiter plates at a density of 1 x $10^{4}$ cells per well and allowed to adhere for $24 \mathrm{~h}$. After this time the culture medium was removed and HeLa cells were incubated with rhsTRAIL at the concentrations of $100 \mathrm{ng} / \mathrm{ml}$ for 18 hours with or without flavonoids. The tested polyphenolic compounds were added over a concentration range of $10-50 \mu \mathrm{M}$. Working dilutions were freshly prepared on the day of testing. After 18 hours of incubation the cell growth rate was evaluated by MTT assays (Sigma Chemical Company, St. Louis, MO) [29]. The spectrophotometric absorbance of each well was measured by microculture plate reader with the test wavelength of $550 \mathrm{~nm}$. The percent cytotoxicity was calculated by the formula, percent cytotoxicity = (1- (absorbance of experimental wells/absorbance of control wells)) x 100.

The results are expressed as $\mathrm{IC}_{50}$, which is the concentration necessary for $50 \%$ inhibition. The $\mathrm{IC}_{50}$ values for the combination of each compound with TRAIL are calculated from dose response curves using linear regression analysis by fitting the test concentrations that give percentage of inhibition values above and below the reference value (50\%).

\subsection{LDH (lactate dehydrogenase) release assay}

LDH is a stable cytosolic enzyme that is released upon membrane damage. LDH activity was measured using a commercial cytotoxicity assay kit (Roche Diagnostics GmbH, Mannheim, Germany), in which released LDH in culture supernatants is measured with a coupled enzymatic assay, resulting in conversion of a tetrazolium salt into red formazan product. The cells were treated with various concentrations of flavonoids and/or rhsTRAIL for indicated period of time. The sample solution (supernatant) was removed and LDH released from cells was measured in culture medium [30]. Maximal release was obtained after treating control cells with 1\% Triton X-100 (Sigma Chemical Company, St. Louis, MO) for 10 minutes at room temperature. The necrotic percentage was expressed using the formula, (sample value/maximal release) x 100\%.

\subsection{Detection of apoptosis}

Apoptotic cells were quantified by microscopic method using Apoptotic \& Necrotic \& Healthy Cells Quantification Kit from Biotium, Inc. (Hayward, CA, USA) according to the manufacturer's instruction. HeLa cells were washed with PBS and were detached from cell culture wells by trypsin. Next the cells were centrifuged to discard supernatant, washed with PBS and resuspended in Binding Buffer (100 $\mu \mathrm{l} /$ sample). To each tube were added $5 \mu \mathrm{l}$ of FITC-Annexin $\mathrm{V}, 5 \mu \mathrm{l}$ of Ethidium Homodimer III and $5 \mu \mathrm{l}$ of Hoechst 33342 solutions. The samples were incubated at room temperature for 15 minutes in the dark. After staining the cells were washed with Binding Buffer and placed on a 
glass slide and covered with a glass coverslip. The stained cells were observed under a fluorescence inverted microscope IX51 (Olympus, Tokyo, Japan) using filter set for FITC, TRITC and DAPI. The healthy cells emitted blue (stained by Hoechst), apoptotic cells emitted green and blue (stained by FITC-Annexin V and Hoechst) and necrotic cells emitted red and blue fluorescence (stained with Ethidium Homodimer and Hoechst). Cells stained with triple colors blue, red and green were dead cells progressing from apoptotic cell population. The cells were counted and apoptotic cells were expressed as percentage of total cells.

The microscopic studies were performed at $50 \mu \mathrm{M}$ concentration of flavonoids with or without TRAIL.

\subsection{Statistical analysis}

Each test point was measured in quadruplicate in three individual experiments. The results are expressed as $\mathrm{IC}_{50}$, a concentration necessary for $50 \%$ of inhibition. Each result is a mean value of $\mathrm{IC}_{50}$ \pm SD from three separate experiments. The $\mathrm{IC}_{50}$ values for each flavonoid were calculated from dose response curves using linear regression analysis by fitting the test concentrations that gave percentage of inhibition values above and below the reference value (50\%) using PHARM/PCS - version 4 Pharmacologic Calculation System based on "Manual of paharmacologic calculation with computer programs”, $2^{\text {nd }}$ edition by R.J. Tallarida and R.B. Murray, Springer Verlag, New York, 1986.

The results of microscopic studies are expressed as mean values \pm SD from three separate experiments. The data was analyzed using Student's $t$ test. Differences were considered to be statistically significant from the controls at $P<0.05$.

\section{References}

1. Havesteen, B. The Flavonoids, a class of natural products oh high pharmacological potency. Biochem. Pharmacol. 1983, 32, 1141-1148; DOI 10.1016/0006-2952(83)90262-9; PubMed 6342623.

2. Middleton, E. The Flavonoids. TIPS. 1984, 5, 335-338.

3. Middleton, E.; Kandaswami, C.; Theoharides, T.C. The effect of plant flavonoids on mammalian cells: implications for inflammation, heart disease and cancer. Pharmacol. Rev. 2000, 52, 673751; PubMed 11121513.

4. Kanadaswami, C.; Lee, L.T.; Lee, P.P.; Hwang, J.J.; Ke, F.C.; Huang, Y.T.; Lee, M.T. The antitumor activities of flavonoids. In Vivo 2005, 19, 895-909; PubMed 16097445.

5. Thomasset, S.C.; Berry, D.P.; Garcea, G.; Marczylo, T.; Steward, W.P.; Gescher, A.J. Dietary polyphenolic phytochemicals - promising cancer chemopreventive agents in humans? A review of their clinical properties. Int. J. Cancer 2007, 120, 451-458; DOI 10.1002/ijc.22419; PubMed 17131309.

6. Hemaisvarya, S.; Doble, M. Potential synergism of natural products in the treatment of cancer. Phytother. Res. 2006, 20, 239-249; DOI 10.1002/ptr.1841; PubMed 16557604.

7. Aggarwal, B.B.; Shishodia, S. Molecular targets of dietary agents of prevention and therapy of cancer. Biochem. Pharmacol. 2006, 71, 1397-1421; DOI 10.1016/j.bcp.2006.02.009; PubMed 16563357. 
8. Nozawa, F.; Itami, A.; Saruc, M.; Kim, M.; Standom, J.; Picha, K.S.; Cowan, K.H.; Pour, P.M. The combination of tumor necrosis factor related apoptosis inducing ligand (TRAIL/Apo2L) and genistein is effective in inhibiting pancreatic cancer growth. Pancreas 2004, 29, 45-52; DOI 10.1097/00006676-200407000-00055; PubMed 15211111.

9. Shi, R.X.; Ong, C.N.; Shen, H.M. Protein kinase C and X-linked inhibitor of apoptosis protein degradation contribute to the sensitization effect of luteolin on tumor necrosis factor-related apoptosis-inducing ligand induced apoptosis in cancer cells. Cancer Res. 2005, 65, 7815-7823; DOI 10.1158/0008-5472.CAN-04-2749; PubMed 16140950.

10. Horinaka, M.; Yoshida, T.; Shiraishi, T.; Nakata, S.; Wakada, M.; Nakanishi, R.; Nishino, H.; Sakai, T. The combination of TRAIL and luteolin enhances apoptosis in human cervical cancer HeLa cells. Biochem. Biophys. Res. Commun. 2005, 333, 833-838; DOI 10.1016/j.bbrc.2005.05.179; PubMed 15963948.

11. Horinaka, M.; Yoshida, T.; Shiraishi, T.; Nakata, S.; Wakada, M.; Nakanishi, R.; Nishino, H. Luteolin induces apoptosis via death receptor 5 upregulation in human malignant tumor cells. Oncogene. 2005, 24, 7180-7189; DOI 10.1038/sj.onc.1208874; PubMed 16007131.

12. Kim, Y.H.; Lee, Y.J. TRAIL apoptosis is enhanced by quercetin through Akt dephosphorylation. J. Cell Biochem. 2007, 100, 998-1009; PubMed 17031854.

13. Chen, W.; Wang, X.; Zhuang, J.; Lin, Y. Induction of death receptor 5 and suppression of survivin contribute to sensitization oh TRAIL-induced cytotoxicity by quercetin in non-small cell lung cancer cells. Carcinogenesis 2007, 4, ahead of print.

14. Horinaka, M.; Yoshida, T.; Shiraishi, T.; Nakata, S.; Wakada, M.; Sakai, T. The dietary flavonoid apigenin sensitizes malignant tumor cells to tumor necrosis factor-related apoptosis-inducing ligand. Mol. Cancer Ther. 2006, 5, 945-951; PubMed 16648565.

15. Kuo, P.L.; Hsu, Y.L.; Lin, T.C.; Lin, C.C. The antiproliferative activity of prodelphidin B-2' 3'-Ogallate from green tea leaf is through cell cycle arrest and Fas-mediated apoptotic pathway in A549 cells. Food Chem. Toxicol. 2005, 43, 315-323; PubMed 15621344.

16. Zheng, P.W.; Chiang, L.C.; Lin, C.C. Apigenin induces apoptyosis through p53-dependent pathway in human cervical carcinoma cells. Life Sci. 2005, 76, 1367-1379; PubMed 15670616.

17. Pan, M.H.; Lai, P.C.; Hsu, P.C.; Wang, Y.J. Acacetin induces apoptosis in human gastric carcinoma cells accompanied by activation of caspase cascades and production of reactive oxygen species. J. Agric. Food Chem. 2005, 53, 620-630; PubMed 15686411.

18. Shi, R.X.; Ong, C.N.; Shen, H.M. Luteolin sensitizes tumor necrosis factor-alpha apoptosis in human tumor cells. Oncogene. 2004, 23, 7712-7721; PubMed 15334063.

19. Kuo, P.L.; Lin, C.C. Green tea constituent (-)-epigallocatechin-3-gallate Inhibits Hep G2 cell proliferation and induces apoptosis through p53-dependent and Fas-mediated pathways. Biomed. Sci. 2003, 10, 219-227.

20. Ashkenazi, A.; Pai, R.; Fong, S.; Leung, S.; Lawrence, D.; Marsters, S.; Blackie, C.; Chang, L.; McMurtrey, A.E.; Hebert, A.; DeForge, L.; Koumenis, I.; Lewis, D.; Harris, D.; Bussiere, J.; Koeppen, H.; Shahrokh, Z.; Schwall, R.H. Safety and antitumor activity of recombinant Apo2 ligand. J. Clin. Invest. 1999, 104, 155-162; PubMed 10411544.

21. Almasan, A.; Ashkenazi, A. Apo2L/TRAIL: apoptosis signaling, biology and potential for cancer therapy. Cytokine Growth Factor Rev. 2003, 14, 337-348; PubMed 12787570. 
22. Zhang, L.; Fang, B. Mechanisms of resistance to TRAIL-induced apoptosis in cancer. Cancer Gene Ther. 2005, 12, 228-227; DOI 10.1038/sj.cgt.7700792; PubMed 15550937.

23. Baud, V.; Karin, M. Signal transduction by tumor necrosis factor and its relatives. Trends Cell Biol. 2001, 11, 372-377; PubMed 11514191.

24. Wajant, H.; Pfizenmaier, K.; Scheurich, P. Tumor necrosis factor signaling. Cell Death Differ. 2003, 10, 45-65; PubMed 12655295.

25. Lee, M.W.; Park, S.C.; Kim, J.H.; Kim, I.K.; Han, K.S.; Kim, K.Y.; Lee, W.B.; Jung, Y.K.; Kim, S.S. The involvement of oxidative stress in tumor necrosis factor (TNF)-related apoptosisinducing ligand (TRAIL)-induced apoptosis in HeLa cells. Cancer Lett. 2002, 182, 75-82; PubMed 12175526.

26. Czuba, Z.P.; Krol, W. The importance of hydroxyl substituent in position 4' in flavonoids for modulation of chemiluminescence generated by an enzymatic system (horseradish peroxidase luminol - hydrogen peroxide). Curr. Top. Biophys. 1996, 20S, 38-41.

27. Shakibaei, M.; Schulze-Tanzil, G.; Takada, Y.; Aggarwal, B.B. Redox regulation of apoptosis by member of the TNF superfamily. Antioxid. Redox Signal. 2005, 7, 482-496; PubMed 15706096.

28. Shen, H.M.; Pervaiz, S. TNF receptor superfamily-induced cell death: redox-dependent execution. FASEB J. 2006, 20, 1589-1598; PubMed 16873882.

29. Cell proliferation kit I (MTT). Instruction manual. Version 3. Roche Applied Science, Germany, 2003.

30. Cytotoxicity detection kit (LDH). Instruction manual. Version 5. Roche Applied Science, Germany, 2004.

(c) 2008 by MDPI (http://www.mdpi.org). Reproduction is permitted for noncommercial purposes. 